\title{
Can We Predict the Toxicity and Response to Thiopurines in Inflammatory Bowel Diseases?
}

\author{
Raphael P. Luber*, Sailish Honap, Georgina Cunningham and Peter M. Irving \\ Department of Gastroenterology, Guy's and St. Thomas' NHS Foundation Trust, London, United Kingdom
}

Thiopurines are a cheap, effective treatment option in the management of inflammatory bowel disease (IBD). However, with the growing choice of targeted therapies available, as well as the well-documented toxicities of thiopurines, the role of thiopurines has been questioned. Nevertheless, given their inexpense in an era of spiraling healthcare costs, thiopurines remain an attractive option in the right patients. In the age of personalized medicine, being able to predict patients who will respond as well as those that will develop toxicity to a treatment is vital to tailoring therapy. This review will summarize the available literature with respect to predictors of response and toxicity to thiopurines in order to guide management in IBD. Specifically, toxicities addressed will include myelotoxicity, hepatotoxicity, pancreatitis, alopecia, gastrointestinal and flu-like

OPEN ACCESS

Edited by:

Fernando Gomollón, University of Zaragoza, Spain

Reviewed by: Antonio Lopez-Sanroman, Ramón y Cajal University Hospital, Spain

Fernando Bermejo,

Hospital Universitario de

Fuenlabrada, Spain

*Correspondence:

Raphael P. Luber raphael.luber@gstt.nhs.uk

Specialty section: This article was submitted to

Gastroenterology, a section of the journal

Frontiers in Medicine

Received: 30 September 2019 Accepted: 14 November 2019 Published: 28 November 2019

Citation:

Luber RP, Honap S, Cunningham G and Irving PM (2019) Can We Predict the Toxicity and Response to

Thiopurines in Inflammatory Bowel

Diseases? Front. Med. 6:279.

doi: 10.3389/fmed.2019.00279 symptoms, and complications associated with Epstein-Barr virus. While more work needs to be done to further our ability to predict both response to and side effects from therapies, pharmacogenomic research shows significant promise in its ability to personalize our use of thiopurines.

Keywords: thiopurines, azathioprine, 6-mercaptopurine, inflammatory bowel disease, Crohn's disease, ulcerative colitis, toxicity, response

\section{INTRODUCTION}

Thiopurines, including azathioprine, 6-mercaptopurine and tioguanine, are longstanding therapies within the ever-expanding inflammatory bowel disease (IBD) treatment armamentarium (1-5). They have shown themselves to be effective in the maintenance of remission in patients with IBD and have also resulted in reductions in the need for surgery, post-operative recurrence and IBD-related colorectal cancer risk. In addition, they improve pharmacokinetics of anti-tumor necrosis factor agents when used in combination with these therapies (6). Given their efficacy, oral delivery, and low cost they are frequently used as pre-biologic treatments in both Crohn's disease (CD) and ulcerative colitis (UC) and many clinicians have extensive experience with their use. However, up to $60 \%$ of patients will either respond inadequately or will develop toxicity to thiopurines (7), necessitating their cessation or treatment modification. With the continual advent of new targeted biologic therapies, the role of thiopurines in the current era is, therefore, being questioned (8).

The ability to use clinical and biologic characteristics of an individual to predict their disease course and to personalize their treatment pathway is the aim of precision medicine (9). An essential component of this goal is the ability to predict those who are more likely to respond or develop toxicity to a particular therapy, in order to improve the safety and efficacy of treatment choices. While some authorities suggest that treatment choices should not be influenced by cost, the compounding prevalence of IBD in conjunction with the increasing burden of drug costs mean 
that such an approach is perhaps naïve within the context of finite resources. Thus, optimizing the use of inexpensive treatments like thiopurines could have significant financial advantages to health services.

While thiopurines are still felt to have a role in the current era $(8,10)$, our ability to tailor their use to a population which will both tolerate them and achieve the treatment goals that our new treatment paradigms demand will determine their use in the future. This article aims to summarize the available evidence with respect to clinical, genetic, and biological predictors of response and toxicity to thiopurines.

\section{PREDICTORS OF TOXICITY}

Thiopurine use is undoubtedly hindered by the high incidence of adverse drug reactions which affect up to $25 \%$ of people who take them, resulting in drug discontinuation in $17 \%$ of patients (11). Side effects often occur in the first few months. Accordingly, the ability to predict which patients are likely to develop these potentially serious side effects would be of great use in clinical practice.

\section{Thiopurine-Induced Myelotoxicity}

Thiopurine-induced myelotoxicity (TIM) is one of the most serious thiopurine-induced side effects and can occur at any time during treatment. In some patients this can lead to life threatening bone marrow suppression. Whilst leucopenia is the commonest hematological abnormality, thrombocytopenia, and pancytopenia can rarely occur. In a review of 66 studies, including more than 8,000 thiopurine-treated patients, the incidence rate of drug-induced myelotoxicity was $3 \%$ per patient year of treatment (12). In East Asian populations, however, the incidence of myelotoxicity can be as high as 15\% (13).

The prodrug azathioprine is non-enzymatically converted to 6-mercaptopurine (6MP) and then through competing pathways is metabolized into thioguanine nucleotides (TGNs). TGNs exert their immunosuppressive effect by interfering with DNA replication of the most actively dividing cells, as well as by inducing apoptosis in activated and pre-activated $\mathrm{T}$ lymphocytes (14). Thiopurine-S-methyltransferase (TPMT) is an enzyme which catalyzes the methylation of 6-MP to 6methylmercaptopurine (6-MMP), a non-therapeutic metabolite. Approximately 1 in 10 people have intermediate TPMT activity due to heterozygosity of TPMT, and 1 in 300 have TPMT deficiency, which is inherited in an autosomal recessive manner (15). In heterozygotes, TPMT*3A is the commonest mutant allele (85\%), whilst $\mathrm{TPMT}^{*} 2$ and $\mathrm{TPMT}^{*} 3 \mathrm{C}$ are rarer (15). TIM is strongly linked to low TPMT enzyme activity and high 6-TGN blood levels (16). Standard thiopurine dosing in heterozygous or TPMT-deficient patients leads to 6-TGN accumulation in the bone marrow and potentiates the risk of life-threatening bone marrow suppression.

TPMT phenotype testing is commonplace in clinical practice and is one of the most frequently used pharmacogenetic tests. TPMT enzyme assays can also be used alongside genotyping, which is used less commonly, to assess activity where rarer mutations may be missed on genotyping. Genetic testing is useful in patients with renal failure and reduced clearance of TPMT inhibitors, where enzyme activity can be falsely low. However, routine genotyping is not commonplace with some evidence suggesting that this may not be cost-effective compared with standard phenotyping $(17,18)$. TIM can also occur with normal TPMT activity necessitating regular full blood count monitoring in clinical practice to allow dose reduction or drug cessation in cases of TIM. A meta-analysis found that low TPMT is associated with TIM but not hepatotoxicity or pancreatitis (19).

Nudix hydrolase 15 (NUDT15) variants have also been linked to altered thiopurine metabolism and TIM (20). Mutations of NUDT15, which occur more frequently in the East Asian population, lead to reduced enzyme activity and TIM in a TGN-independent manner $(20,21)$. More recently, variants in NUDT15 were found to be associated with increased risk of TIM among IBD patients of European ancestry (22). Furthermore, patients with mutations in both TPMT and NUDT15 developed TIM faster (22). These findings highlight the importance of NUDT15 genotyping, alongside TPMT phenotype, or genotype testing. This is supported by a recent systematic review and meta-analysis (23), and recently published guidelines provide suggested dosing regimens in patients with TPMT or NUDT15 variants (24).

It may also be possible to predict early myelotoxicity by measuring thiopurine metabolites soon after treatment commencement. In a Dutch study, patients with 6-TGN levels of more than $213 \mathrm{pmol} / 8 \times 10^{8}$ red blood cells (RBC) and 6-MMP levels higher than $3,525 \mathrm{pmol} / 8 \times 10^{8} \mathrm{RBC}$ measured after 1 week of thiopurine initiation were six times more likely to have early TIM (25).

\section{Thiopurine-Induced Hepatotoxicity}

Thiopurine-induced hepatotoxicity (TIH) is an uncommon but important side effect of thiopurine use. Most commonly, this results in increased transaminase levels, which resolves with dose reduction or drug discontinuation. Less commonly, TIH manifests as idiosyncratic cholestasis or nodular regenerative hyperplasia. A systematic review, which included 3,485 patients, described an overall prevalence of $3.4 \%$ for $\mathrm{TIH}$ (26). In a pediatric cohort, TIH was found to be strongly correlated with 6-MMP levels with a 3-fold increased risk at levels $>5,700$ $\mathrm{pmol} / 8 \times 10^{8} \mathrm{RBC}(16)$. In a Dutch cohort study of 270 adult patients, when TIH occurred it did so within 8 weeks in $85 \%$ of patients and was associated with elevated 6-MMP levels (27). Furthermore, in the same study, a predictive algorithm based on a week one 6-MMP level $>3,615 \mathrm{pmol} / 10^{8} \mathrm{RBC}$, older age, male gender and higher BMI yielded an area under the curve of 0.83 (95\% CI: 0.75-0.91) for hepatotoxicity risk. Another study found elevated 6-MMP levels in those with TIH but sensitivity and specificity were poor (28). These studies highlight that whilst 6-MMP levels are associated with TIH, intervention should be reserved for those in whom the high 6-MMP levels are associated with abnormal liver function tests.

Nodular regenerative hyperplasia is a condition characterized by diffuse nodulation of the hepatic parenchyma, leading to portal hypertension. Although its natural history is not clearly understood, it can occur in patients treated with purine analogs, 
particularly tioguanine (29). Studies have shown that this is more likely to occur in male patients with a stricturing small bowel disease phenotype (30-32). Although rare, regular monitoring of blood tests is necessary, particularly for the gradual onset of thrombocytopenia signaling portal hypertension.

Although there is no validated genetic predictor of $\mathrm{TIH}$, there is a worldwide collaborative effort to achieve this aim. This includes the Helmsley IBD Exome Sequencing Program (33), and the Predicting Serious Side Effects in Gastroenterology (PRED4), conducted by the UK IBD Genetics Consortium.

\section{Thiopurine-Induced Pancreatitis}

Pancreatitis occurs in $<5 \%$ of patients treated with azathioprine or mercaptopurine and often occurs in the first month of treatment $(11,34,35)$. Reinstating therapy upon recovery leads to recurrent pancreatitis, so indefinite drug withdrawal is required although a switch to tioguanine may be considered $(34,36)$. Thiopurine-induced pancreatitis (TIP) is an idiosyncratic drug reaction and the pathophysiology is unknown. Interestingly, and for unclear reasons, patients treated with thiopurines for IBD have a greater incidence of TIP compared to those treated for other diseases (37). However, TIP is almost always mild in IBD patients and generally responds rapidly to drug withdrawal (38). Smoking has been found to be a strong risk factor in TIP (39), along with having $\mathrm{CD}(11,38)$.

Two genome wide association studies of patients with TIP found a link to the class II HLA region, with the most significant associations identified being at rs2647087 (40, 41). Patients heterozygous at rs 2647087 have a $9 \%$ risk of developing TIP and homozygotes have a $17 \%$ risk (40) although tests to predict risk of TIP are not yet commonplace in clinical practice. Approximately 76 patients need to be genotyped for rs2647087 to prevent one case of pancreatitis, and given that most cases of TIP run a benign course, there is an argument that screening may not be a cost-effective strategy.

\section{Thiopurine-Induced Alopecia}

Alopecia secondary to thiopurine use is a rare, dose-related adverse event, with an incidence of $1.5 \%$ in patients of Asian descent (13). Whilst clearly not life-threatening, alopecia can have profound psychological effects and increases the risk of non-compliance with therapy. Studies have shown that the NUDT15 variants are associated with risk of thiopurine-induced alopecia $(42,43)$. Therefore, dose reduction in heterozygotes and thiopurine avoidance in homozygotes can mitigate and avoid both TIM and alopecia in this cohort.

\section{Gastrointestinal Toxicity and Flu-Like IIIness}

The most common but least serious adverse effects of thiopurines are gastrointestinal disturbances (nausea, vomiting, abdominal pain) and flu-like symptoms (malaise, fever, myalgia), which are responsible for drug discontinuation in many patients. The flu-like symptoms are likely to be immune-mediated and tend to occur shortly after starting treatment. It is not clear if the reactions are dose-dependent or idiosyncratic. A prospective evaluation of azathioprine-treated IBD patients found that
TPMT heterozygosity strongly predicted GI adverse effects (37\% heterozygous vs. $7 \%$ wild-type TPMT, $P<0.001$ ) (44).

Switching treatment to $6 \mathrm{MP}$ may be one way to curb some of these side effects. An observational study and systematic review demonstrated $60 \%$ of patients intolerant of azathioprine were able to tolerate $6 \mathrm{MP}(45)$. In those ceasing $6 \mathrm{MP}$ due to further adverse effects, 59\% experienced the same side effect as they had with azathioprine.

\section{Serious Complications Associated With Epstein-Barr Virus (EBV)}

The association between thiopurine use and EBV-driven B-cell lymphoma has been understood for many years. A roughly fourfold increase in risk over background has been identified across several studies (46) and, thus, the greatest absolute risk is in those with the highest background risk, i.e., the elderly.

In addition, severe and potentially fatal EBV primary infections and post infectious lymphoproliferative disorders have also been associated with thiopurine use (46-48). This has prompted some to advocate for pre-treatment EBV serology testing and avoidance of thiopurines, if possible, in EBV seronegative individuals (48). In the CESAME study (Cancers Et Surrisque Associé aux Maladies inflammatoires intestinales En France), a low incidence of 0.1 per 1,000 patient years of postmononucleosis lymphomas was observed overall, rising to 3 per 1,000 patient years when considering young males, seronegative for EBV (46). In addition, in a pediatric population of 5,766 participants, there were 5 cases of haemophagocytic lymphohistiocytosis ( $\mathrm{HLH}$ ), all exposed to thiopurines, equating to an incidence of 0.2 per 1,000 patient years (49).

Despite the majority of pediatric patients being EBV seronegative at initiation of thiopurines (50), the incidence of HLH is low. Furthermore, as EBV is not the sole trigger of serious infectious complications like HLH (47), some argue against routine pre-thiopurine EBV testing $(51,52)$. Nevertheless, given the potentially severe, albeit rare, consequences of primary EBV infections or post infectious lymphoproliferative disorders in patients on thiopurines, coupled with the increasing availability of therapeutic alternatives, we carefully balance the risk and benefit of thiopurine use in EBV negative patients, but do not avoid its use completely.

\section{PREDICTORS OF RESPONSE TO THIOPURINES}

The ability to predict who will respond to thiopurine therapy and to maximize likelihood of response earlier in the disease course would enable clinicians to tailor therapy sooner, with the aim of altering the natural history of the disease (53). Heterogeneity in definitions of response, as well as the tenuous relationship between clinical response and mucosal activity make interpretation of the literature challenging with respect to prediction of response. While thiopurine metabolite monitoring enables personalized dosing, it obviously relies on patients having already commenced the therapy; pre-treatment predictors are the ideal. 


\section{Clinical Predictors}

The relatively small numbers of patients in azathioprine efficacy studies has limited our ability to identify clinical predictive factors of response $(3,54)$. As such, clinical predictive factors have thus far not been incorporated into clinical practice in a significant way. A number of retrospective studies have identified factors that may predict response, or lack of it, although their results must be interpreted with caution.

Some of the largest studies addressing predictive factors of thiopurine response have yielded conflicting results in terms of disease type (CD vs. UC) and location. In a single center review of 622 patients, remission rates in those who completed 6 months of azathioprine were highest in UC patients compared to CD ( $87 \%$ vs. $64 \%, p=0.0001$ ) (55). In CD cases specifically, colonic distribution was associated with a higher rate of clinical remission compared to other distributions. This finding was mirrored in another study which found that azathioprine caused mucosal healing in $70 \%$ of patients with Crohn's colitis and 54\% with ileitis (56). However, in a study of 139 IBD patients, rates of response to thiopurines were highest in patients with ileal CD (27 responders vs. 2 non-responders, $p=0.003$ ) (57). No difference was found in response rate in other IBD subtypes, although numbers were small.

Body mass index (BMI) has been associated with response, surprisingly with opposite effects in UC and CD. In a large retrospective study $(n=1176)$, patients with $\mathrm{UC}$ with a BMI $<25$ had a lower flare rate after starting azathioprine than those with BMI $>25$, albeit only in those with disease duration $<3$ years (58). In $\mathrm{CD}$, flare rates were similar between BMI groups, however upon azathioprine withdrawal, patients with a BMI $<25$ had higher flare rates than BMI $>25$ (58). It is theorized that adipocytes and fatty tissue may play an immunological role, involved in the physiologic and pathologic regulation of the immune system and inflammation (59). BMI, however, had no effect on thiopurine efficacy in a smaller study (57).

With regard to clinical disease activity, it has been reported that long term clinical response is improved in $\mathrm{CD}$ when azathioprine is commenced when patients are in remission (58). While this may reflect less severe disease, the same difference was not seen in UC. In a Korean study published in abstract form only, however, high Mayo score was associated with thiopurine treatment failure in patients with UC (HR 1.28, 95\% CI 1.04-1.58, $p=0.023$ ) (60). In addition, in a cohort of mixed IBD patients response was associated with shorter duration of disease at the time of commencing azathioprine than non-response ( $47.4 \pm 6.6$ months among responders, vs. $85.4 \pm 14.6$ in non-responders, $p$ $=0.007$ ) (57), suggesting earlier introduction of thiopurines may improve response.

In contrast to these studies, a prospective double-blind trial of patients with a recent ( $<8$ weeks) diagnosis of $\mathrm{CD}$ found that rates of corticosteroid-free clinical remission at week 76 were similar in azathioprine and placebo-treated patients (61). This finding was supported by an open-label French study, in which early ( $<6$ months) administration of azathioprine was no more effective than conventional management (62). Whilst the findings of theses studies need careful interpretation $(63,64)$, the early introduction of thiopurines cannot, therefore, be recommended in all patients with CD.

Ethnicity may also play a role in thiopurine metabolism and response. In an observational study of Chinese patients with UC, standard dose thiopurine ( $>2 \mathrm{mg} / \mathrm{kg} /$ day) was compared to low dose thiopurine therapy $(<2 \mathrm{mg} / \mathrm{kg} /$ day $)$. Cumulative relapsefree survival rates were similar between groups, however a threefold increased risk of leucopenia was seen with standard dosing (65). This may be reflective of variations in genotypes between ethnic groups such as has been seen with variants of NUDT15, associated with an increased risk of leucopenia, which are more commonly found in Asian patients $(22,66)$.

The effect of gender has been conflicting across studies, and likely plays no role. Female gender was found to be associated with thiopurine response by some $(57,67)$, with the opposite found in a pediatric population (68) and no difference in another larger adult population (55).

\section{Thiopurine Metabolites and TPMT}

6-TGN levels have been shown to correlate with efficacy (69), and levels $\geq 235 \mathrm{pmol} / 10^{8} \mathrm{RBC}$ are associated with clinical response and remission in thiopurine monotherapy (16). Meta-analysis data confirm this, showing a higher rate of clinical remission in patients with a 6-TGN above this threshold compared with below (62 vs. $36 \%$, pooled OR 3.3, 95\% CI 1.7-6.3; $p<0.001$ ), as well as higher TGNs in patients in clinical remission vs. active disease $(53,70)$. However, it must be recognized that these data are based upon studies which are small, heterogeneous and generally retrospective (71) and a prospective multicenter study of thiopurine weight-based dosed IBD patients found a poor relationship between TGN and clinical response rate, with no useful TGN cut-off determinable (72).

While a threshold of $235 \mathrm{pmol} / 10^{8} \mathrm{RBC}$ may be sufficient for clinical remission, mucosal healing, increasingly recognized as a more robust, and potentially disease-modifying endpoint (73, 74), may require higher levels. A recent multicenter, international retrospective study showed that 6-TGN levels were associated with mucosal healing, and that a level of $397 \mathrm{pmol} / 10^{8} \mathrm{RBC}$ was $86.7 \%$ specific but only $35.3 \%$ sensitive for mucosal healing (75). However, higher 6-TGN levels are also associated with increased rates of early or late myelotoxicity (23), particularly above 450 $\mathrm{pmol} / 8 \times 10^{8} \mathrm{RBC}(76)$, and so a fine balance exists between response and toxicity. Interestingly, while a lower thiopurine dose may be sufficient for Asian patients, as discussed above, it is the 6-TGN and not the dose that was associated with mucosal healing in a cohort including a large proportion of Chinese patients (75).

The optimal use of thiopurine metabolite levels (6-TGN and 6-MMP) to maximize response, however, is a controversial area, with practices varying across the world (77-79). Observational data support the use of TGN monitoring in non-responding patients, with TGN-directed dose optimization eliciting a response rate of $87-90 \%$ compared to $18-33 \%$ in which treatment was not TGN directed ( $\mathrm{p}<0.001$ for both studies) $(77,80)$. In one retrospective study of 169 patients undergoing thiopurine metabolite testing, the majority (52\%) had subtherapeutic 6-TGN levels and testing resulted in a change in patient treatment in 68\% 
of patients overall and $86 \%$ of patients with active disease and sub-therapeutic levels (81).

However, prospective randomized trials of TGN monitoring vs. standard weight-based dosing in patients commencing on thiopurines for IBD have failed to show benefit $(82,83)$. In a study of 57 patients, rates of clinical remission in TGN-guided vs. standard weight-based dosing groups were similar at 16 and 24 weeks (82). However, it should be noted that mean 6-TGN levels in the standard group ranged between 216 and $266 \mathrm{pmol} / 10^{8}$ RBC. This is in contrast to real world data suggesting $50 \%$ of thiopurine-treated patients are not receiving the appropriate weight-based dose, corresponding to $40-50 \%$ being underdosed on TGN criteria $(80,81)$. In another prospective study of 50 patients, clinical remission rates at week 16 were higher in the TGN-based vs. weight-based dosing. However, this failed to achieve statistical significance, possibly due to underpowering ( $40 \%$ vs. $16 \%, p=0.11$ ) (83).

Thiopurine metabolite testing is also helpful when preferential 6-MMP metabolism or "shunting" occurs. This phenomenon is associated with reduced efficacy and increased side effects (84). Fortunately, it can be overcome with a reduction in dose of the thiopurine and the introduction of allopurinol (85-87). Indeed, commencing low dose thiopurine-allopurinol combination therapy at thiopurine initiation, regardless of TGNs, may achieve higher response rates and reduced side effects (88).

While measuring 6-TGN may be useful for optimizing response, it may also be useful for predicting a lack of response. In patients with active disease on thiopurine therapy, persistence despite a therapeutic 6-TGN is unlikely to result in success (80), necessitating treatment alteration.

TPMT activity has also been assessed with regards to its role in predicting response. In a study of 39 patients with IBD, patients with TMPT activity $<30.5 \mathrm{EU} / \mathrm{mL}$ were more likely to have a clinical response to thiopurines than those with higher TPMT activity (65 vs. $29 \%, p=0.05$ ), independent of TGN values. In patients with TPMT activity $<30.5 \mathrm{EU} / \mathrm{mL}$ and a therapeutic 6-TGN, $100 \%$ responded compared to $25 \%$ with higher TPMT activity and low 6-TGN $(p=0.01)$ (89). Others, however, have found no relationship between TPMT activity and clinical response (72). Given biologic plausibility as well as evidence that low TMPT activity is associated with higher 6-TGN (16), clinical response is more likely to be related to TGN than the TPMT activity.

\section{Genetic Predictors}

TPMT polymorphisms have not been associated with response $(67,90)$. In a prospective multicenter trial of 783 patients

\section{REFERENCES}

1. Willoughby J, Beckett J, Kumar P, Dawson A. Controlled trial of azathioprine in Crohn's disease. Lancet. (1971) 298:944-7. doi: 10.1016/S0140-6736(71)90268-6

2. Rosenberg JL, Levin B, Wall AJ, Kirsner JB. A controlled trial of azathioprine in Crohn's disease. Am J Dig Dis. (1975) 20:721-6. doi: 10.1007/BF01070829 randomized to either TPMT polymorphism pre-screening and pre-emptive dose reduction vs. standard treatment, clinical response rates did not differ (90).

A recent small pharmacogenomic study assessed the role of polymorphisms of potential genes of relevance to azathioprine metabolism on clinical response and toxicity to azathioprine in IBD. GSTM1 deletion, a polymorphism of the gene encoding Glutathione-S-transferase, the enzyme responsible for conversion of azathioprine to 6mercaptopurine, was significantly associated with poor response to azathioprine on multivariate analysis albeit with a wide confidence interval (OR 9.22, 95\% CI 1.081-78.62, $p=0.042)(67)$.

Published in abstract form only, a predictive model for achieving corticosteroid free remission with thiopurines at 26 weeks in a pediatric cohort of mixed IBD patients showed promise. Using novel pharmacogenetic genome-wide association study-identified loci, the previously identified IBD susceptibility locus HLA-DRB-1, and clinical features including pANCA positivity, disease duration, and diagnosis of $\mathrm{UC}$ as opposed to $\mathrm{CD}$, the model had an area under the curve for corticosteroid-free remission of 0.985 (68).

\section{CONCLUSION}

Thiopurines remain an effective treatment for IBD, with their relative cost, decades of use and the ability to measure and optimize metabolites maintaining their role in the biologic era. As we strive for an era of personalized medicine and gain further experience with our expanding therapeutic choices, our ability to predict thiopurine response and toxicity, and to tailor therapy accordingly, will determine its future role. While thiopurine metabolite monitoring shows utility in those already commenced on thiopurines, pharmacogenetic testing, which already plays a significant role in preventing toxicity, shows some promise in predicting response.

\section{AUTHOR CONTRIBUTIONS}

RL, SH, and GC wrote and reviewed the manuscript. PI supervised and reviewed the manuscript.

\section{FUNDING}

Please note this is an invited article for Personalizing Treatment In IBD: Hype or Reality In 2020? Fees have been waived by the journal. 
5. Prefontaine E, Macdonald JK, Sutherland LR. Azathioprine or 6mercaptopurine for induction of remission in Crohn's disease. Cochrane Database Syst Rev. (2010) 6:Cd000545. doi: 10.1002/14651858. CD000545.pub3

6. de Boer NK, Peyrin-Biroulet L, Jharap B, Sanderson JD, Meijer B, Atreya I, et al. Thiopurines in inflammatory bowel disease: new findings and perspectives. J Crohn's Colitis. (2017) 12:610-20. doi: 10.1093/ecco-jcc/ jjx181

7. Jharap B, Seinen ML, De Boer N, van Ginkel JR, Linskens RK, Kneppelhout JC, et al. Thiopurine therapy in inflammatory bowel disease patients: analyses of two 8-year intercept cohorts. Inflamm Bowel Dis. (2010) 16:1541-9. doi: 10.1002/ibd.21221

8. Hanauer SB, Sandborn WJ, Lichtenstein GR. Evolving considerations for thiopurine therapy for inflammatory bowel diseases-a clinical practice update: commentary. Gastroenterology. (2019) 156:36-42. doi: 10.1053/j.gastro.2018.08.043

9. Denson LA, Curran M, McGovern DP, Koltun WA, Duerr RH, Kim SC, et al. Challenges in IBD research: precision medicine. Inflamm Bowel Dis. (2019) 25:S31-9. doi: 10.1093/ibd/izz078

10. de Boer NK. Thiopurine therapy in inflammatory bowel diseases: making new friends should not mean losing old ones. Gastroenterology. (2019) 156:11-4. doi: 10.1053/j.gastro.2018.11.039

11. Chaparro M, Ordás I, Cabré E, Garcia-Sanchez V, Bastida G, Peñalva M, et al. Safety of thiopurine therapy in inflammatory bowel disease: long-term follow-up study of 3931 patients. Inflamm. Bowel Dis. (2013) 19:1404-10. doi: 10.1097/MIB.0b013e318281f28f

12. Gisbert JP, Gomollón F. Thiopurine-induced myelotoxicity in patients with inflammatory bowel disease: a review. Am J Gastroenterol. (2008) 103:1783800. doi: 10.1111/j.1572-0241.2008.01848.x

13. Qiu Y, Mao R, Zhang SH, Li MY, Guo J, Chen BL, et al. Safety profile of thiopurines in Crohn disease: analysis of 893 patient-years follow-up in a Southern China cohort. Medicine. (2015) 94:e1513. doi: 10.1097/MD.0000000000001513

14. Tiede I, Fritz G, Strand S, Poppe D, Dvorsky R, Strand D, et al. CD28dependent Racl activation is the molecular target of azathioprine in primary human CD4+ T lymphocytes. J Clin Invest. (2003) 111:1133-45. doi: $10.1172 /$ JCI16432

15. Yates CR, Krynetski EY, Loennechen T, Fessing MY, Tai HL, Pui CH, et al. Molecular diagnosis of thiopurine S-methyltransferase deficiency: genetic basis for azathioprine and mercaptopurine intolerance. Ann Intern Med. (1997) 126:608-14. doi: 10.7326/0003-4819-126-8-199704150-00003

16. Dubinsky MC, Lamothe S, Yang HY, Targan SR, Sinnett D, Théorêt Y, et al. Pharmacogenomics and metabolite measurement for 6-mercaptopurine therapy in inflammatory bowel disease. Gastroenterology. (2000) 118:705-13. doi: 10.1016/S0016-5085(00)70140-5

17. Donnan JR, Ungar WJ, Mathews M, Hancock-Howard RL, Rahman P. A cost effectiveness analysis of thiopurine methyltransferase testing for guiding 6-mercaptopurine dosing in children with acute lymphoblastic leukemia. Pediatr. Blood Cancer. (2011) 57:231-9. doi: 10.1002/pbc.22936

18. Zarca K, Durand-Zaleski I, Loriot MA, Chatellier G, Pallet N. Modeling the outcome of systematic TPMT genotyping or phenotyping before azathioprine prescription: a cost-effectiveness analysis. Mol Diagn Ther. (2019) 23:429-38. doi: 10.1007/s40291-019-00398-x

19. Dong XW, Zheng Q, Zhu MM, Tong JL, Ran ZH. Thiopurine Smethyltransferase polymorphisms and thiopurine toxicity in treatment of inflammatory bowel disease. World J Gastroenterol. (2010) 16:3187-95. doi: 10.3748/wjg.v16.i25.3187

20. Moriyama T, Nishii R, Perez-Andreu V, Yang W, Klussmann FA, Zhao X, et al. NUDT15 polymorphisms alter thiopurine metabolism and hematopoietic toxicity. Nat Genet. (2016) 48:367-73. doi: 10.1038/ng.3508

21. Zhang A, Yang J, Wang H, Lu J, Tang S, Zhang X. Association of NUDT15 c. 415C > T allele and thiopurine-induced leukocytopenia in Asians: a systematic review and meta-analysis. Ir J Med Sci. (2018) 187:145-53. doi: 10.1007/s11845-017-1608-x

22. Walker GJ, Harrison JW, Heap GA, Voskuil MD, Andersen V, Anderson CA, et al. Association of genetic variants in NUDT15 with thiopurine-induced myelosuppression in patients with inflammatory bowel disease. JAMA. (2019) 321:773-85. doi: 10.1001/jama.2019.0709
23. van Gennep S, Konté K, Meijer B, Heymans MW, D’Haens GR, Löwenberg $\mathrm{M}$, et al. Systematic review with meta-analysis: risk factors for thiopurineinduced leukopenia in IBD. Aliment Pharmacol Ther. (2019) 50:484-506. doi: 10.1111/apt.15403

24. Relling MV, Schwab M, Whirl-Carrillo M, Suarez-Kurtz G, Pui CH, Stein CM, et al. Clinical pharmacogenetics implementation consortium guideline for thiopurine dosing based on TPMT and NUDT 15 genotypes: 2018 update. Clin Pharmacol Ther. (2019) 105:1095-105. doi: 10.1002/ cpt.1304

25. Wong DR, Coenen MJ, Vermeulen SH, Derijks LJ, van Marrewijk CJ, Klungel $\mathrm{OH}$, et al. Early assessment of thiopurine metabolites identifies patients at risk of thiopurine-induced leukopenia in inflammatory bowel disease. J Crohn's Colitis. (2017) 11:175-84. doi: 10.1093/ecco-jcc/jjw130

26. Gisbert JP, González-Lama Y, and Maté J. Thiopurine-induced liver injury in patients with inflammatory bowel disease: a systematic review. Am J Gastroenterol. (2007) 102:1518-27. doi: 10.1111/j.1572-0241.2007.01187.x

27. Wong DR, Coenen M, Derijks L, Vermeulen S, van Marrewijk CJ, Klungel $\mathrm{O}$, et al. Early prediction of thiopurine-induced hepatotoxicity in inflammatory bowel disease. Aliment Pharmacol Ther. (2017) 45:391-402. doi: 10.1111/apt.13879

28. Shaye OA, Yadegari M, Abreu MT, Poordad F, Simon K, Martin $\mathrm{P}$, et al. Hepatotoxicity of 6-mercaptopurine (6-MP) and azathioprine (AZA) in adult IBD patients. Am J Gastroenterol. (2007) 102:2488-94. doi: 10.1111/j.1572-0241.2007.01515.x

29. Dubinsky MC, Vasiliauskas EA, Singh H, Abreu MT, Papadakis $\mathrm{KA}$, Tran T, et al. 6-thioguanine can cause serious liver injury in inflammatory bowel disease patients. Gastroenterology. (2003) 125:298-303. doi: 10.1016/S0016-5085(03)00938-7

30. Vernier-Massouille G, Cosnes J, Lemann M, Marteau P, Reinisch W, Laharie D, et al. Nodular regenerative hyperplasia in patients with inflammatory bowel disease treated with azathioprine. Gut. (2007) 56:1404-9. doi: 10.1136/gut.2006.114363

31. Seksik P, Mary JY, Beaugerie L, Lémann M, Colombel JF, Vernier-Massouille $\mathrm{G}$, et al. Incidence of nodular regenerative hyperplasia in inflammatory bowel disease patients treated with azathioprine. Inflamm Bowel Dis. (2010) 17:565-72. doi: 10.1002/ibd.21330

32. Simsek M, Meijer B, Ramsoekh D, Bouma G, van der Wouden EJ, den Hartog $\mathrm{B}$, et al. Clinical course of nodular regenerative hyperplasia in thiopurine treated inflammatory bowel disease patients. Clin Gastroenterol Hepatol. (2019) 17:568-70. doi: 10.1016/j.cgh.2018.05.009

33. McGovern DP, Daly MJ. P164 Using exome sequencing to expand the genetic architecture of inflammatory bowel disease. Gastroenterology. (2018) 154:S88. doi: 10.1053/j.gastro.2017.11.216

34. Haber CJ, Meltzer SJ, Present DH, Korelitz BI. Nature and course of pancreatitis caused by 6-mercaptopurine in the treatment of inflammatory bowel disease. Gastroenterology. (1986) 91:982-6. doi: 10.1016/0016-5085(86)90703-1

35. Schwab M, Schäffeler E, Marx C, Fischer C, Lang T, Behrens $\mathrm{C}$, et al. Azathioprine therapy and adverse drug reactions in patients with inflammatory bowel disease: impact of thiopurine Smethyltransferase polymorphism. Pharmacogenetics. (2002) 12:429-36. doi: 10.1097/00008571-200208000-00003

36. Bonaz B, Boitard J, Marteau P, Lemann M, Coffin B, Flourie B, et al. Tioguanine in patients with Crohn's disease intolerant or resistant to azathioprine/mercaptopurine. Aliment Pharmacol Ther. (2003) 18:401-8. doi: 10.1046/j.1365-2036.2003.01683.x

37. Weersma R, Peters F, Oostenbrug L, Van den Berg A, Van Haastert M, Ploeg $\mathrm{R}$, et al. Increased incidence of azathioprine-induced pancreatitis in Crohn's disease compared with other diseases. Aliment Pharmacol Ther. (2004) 20:843-50. doi: 10.1111/j.1365-2036.2004.02197.x

38. Bermejo F, Lopez-Sanroman A, Taxonera C, Gisbert JP, Perez-Calle JL, Vera I, et al. Acute pancreatitis in inflammatory bowel disease, with special reference to azathioprine-induced pancreatitis. Aliment Pharmacol Ther. (2008) 28:6238. doi: 10.1111/j.1365-2036.2008.03746.x

39. Teich N, Mohl W, Bokemeyer B, Bündgens B, Büning J, Miehlke S, et al. Azathioprine-induced acute pancreatitis in patients with inflammatory bowel diseases-a prospective study on incidence and severity. J Crohn's Colitis. (2015) 10:61-8. doi: 10.1093/ecco-jcc/jjv188 
40. Heap GA, Weedon MN, Bewshea CM, Singh A, Chen M, Satchwell JB, et al. HLA-DQA1-HLA-DRB1 variants confer susceptibility to pancreatitis induced by thiopurine immunosuppressants. Nat Genet. (2014) 46:1131-4. doi: 10.1038/ng.3093

41. Wilson A, Jansen LE, Rose RV, Gregor JC, Ponich T, Chande N, et al. HLA-DQA1-HLA-DRB1 polymorphism is a major predictor of azathioprineinduced pancreatitis in patients with inflammatory bowel disease. Aliment Pharmacol Ther. (2018) 47:615-20. doi: 10.1111/apt.14483

42. Kakuta Y, Naito T, Onodera M, Kuroha M, Kimura T, Shiga H, et al. NUDT15 R139C causes thiopurine-induced early severe hair loss and leukopenia in Japanese patients with IBD. Pharmacogenomics J. (2016) 16:280-5. doi: $10.1038 /$ tpj.2015.43

43. Lee YJ, Hwang EH, Park JH, Shin JH, Kang B, Kim SY. NUDT15 variant is the most common variant associated with thiopurineinduced early leukopenia and alopecia in Korean pediatric patients with Crohn's disease. Eur J Gastroenterol Hepatol. (2016) 28:475-8. doi: 10.1097/MEG.0000000000000564

44. Ansari A, Arenas M, Greenfield S, Morris D, Lindsay J, Gilshenan K, et al. Prospective evaluation of the pharmacogenetics of azathioprine in the treatment of inflammatory bowel disease. Aliment Pharmacol Ther. (2008) 28:973-83. doi: 10.1111/j.1365-2036.2008.03788.x

45. Kennedy N, Rhatigan E, Arnott I, Noble C, Shand A, Satsangi J, et al. A trial of mercaptopurine is a safe strategy in patients with inflammatory bowel disease intolerant to azathioprine: an observational study, systematic review and meta-analysis. Aliment Pharmacol Ther. (2013) 38:1255-66. doi: 10.1111/apt.12511

46. Beaugerie L, Brousse N, Bouvier AM, Colombel JF, Lémann M, Cosnes J, et al. Lymphoproliferative disorders in patients receiving thiopurines for inflammatory bowel disease: a prospective observational cohort study. Lancet. (2009) 374:1617-25. doi: 10.1016/S0140-6736(09)61302-7

47. Fries W, Cottone M, Cascio A. Systematic review: macrophage activation syndrome in inflammatory bowel disease. Aliment Pharmacol Ther. (2013) 37:1033-45. doi: 10.1111/apt.12305

48. Louis E, Irving P, Beaugerie L. Use of azathioprine in IBD: modern aspects of an old drug. Gut. (2014) 63:1695-9. doi: 10.1136/gutjnl-2013-306711

49. Hyams JS, Dubinsky MC, Baldassano RN, Colletti RB, Cucchiara S, Escher $\mathrm{J}$, et al. Infliximab is not associated with increased risk of malignancy or hemophagocytic lymphohistiocytosis in pediatric patients with inflammatory bowel disease. Gastroenterology. (2017) 152:1901-14.e1903. doi: 10.1053/j.gastro.2017.02.004

50. Gordon J, Ramaswami A, Beuttler M, Jossen J, Pittman N, Lai J, et al. EBV status and thiopurine use in pediatric IBD. J Pediatr Gastroenterol Nutr. (2016) 62:711-4. doi: 10.1097/MPG.0000000000001077

51. Barnes EL, Herfarth HH. The usefulness of serologic testing for epsteinbarr virus before initiation of therapy for inflammatory bowel disease. Gastroenterology. (2017) 153:1167. doi: 10.1053/j.gastro.2017.04.055

52. Chapman S, El-Matary W. Screening for epstein-barr virus status and risk of hemophagocytic lymphohistiocytosis in children with inflammatory bowel disease on azathioprine. Gastroenterology. (2017) 153:1167-8. doi: 10.1053/j.gastro.2017.07.052

53. Estevinho MM, Afonso J, Rosa I, Lago P, Trindade E, Correia L, et al. A systematic review and meta-analysis of 6-thioguanine nucleotide levels and clinical remission in inflammatory bowel disease. J Crohn's Colitis. (2017) 11:1381-92. doi: 10.1093/ecco-jcc/jjx089

54. Bouhnik Y, Scemama G, Taï R, Matuchansky C, Rambaud J, Lémann $\mathrm{M}$, et al. Long-term follow-up of patients with Crohn's disease treated with azathioprine or 6-mercaptopurine. Lancet. (1996) 347:215-9. doi: 10.1016/S0140-6736(96)90402-X

55. Fraser AG, Orchard TR, Jewell DP. The efficacy of azathioprine for the treatment of inflammatory bowel disease: a 30 year review. Gut. (2002) 50:485-9. doi: 10.1136/gut.50.4.485

56. D'Haens G, Geboes K, Rutgeerts P. Endoscopic and histologic healing of Crohn's (ileo-) colitis with azathioprine. Gastrointest Endosc. (1999) 50:66771. doi: 10.1016/S0016-5107(99)80017-0

57. Costantino G, Furfaro F, Belvedere A, Alibrandi A, Fries W. Thiopurine treatment in inflammatory bowel disease: response predictors, safety, and withdrawal in follow-up. J Crohn's Colitis. (2012) 6:588-96. doi: 10.1016/j.crohns.2011.11.007
58. Holtmann MH, Krummenauer F, Claas C, Kremeyer K, Lorenz D, Rainer O, et al. Significant differences between Crohn's disease and ulcerative colitis regarding the impact of body mass index and initial disease activity on responsiveness to azathioprine: results from a European multicenter study in 1,176 patients. Dig Dis Sci. (2010) 55:1066-78. doi: 10.1007/s10620-009-0846-9

59. Fantuzzi G. Adipose tissue, adipokines, and inflammation. J Allergy Clin Immunol. (2005) 115:911-9. doi: 10.1016/j.jaci.2005.02.023

60. Hwang S, Koo J, Kang K, Lee DW, Lee B, Jeen Y. Predictors of thiopurine treatment failure in ulcerative colitis. J Crohn's Colitis. (2018) 12:S489. doi: 10.1093/ecco-jcc/jix180.874

61. Panes J, Lopez-Sanroman A, Bermejo F, Garcia-Sanchez V, Esteve M, Torres $\mathrm{Y}$, et al. Early azathioprine therapy is no more effective than placebo for newly diagnosed Crohn's disease. Gastroenterology. (2013) 145:766-74.e761. doi: 10.1053/j.gastro.2013.06.009

62. Cosnes J, Bourrier A, Laharie D, Nahon S, Bouhnik Y, Carbonnel F, et al. Early administration of azathioprine vs conventional management of Crohn's Disease: a randomized controlled trial. Gastroenterology. (2013) 145:75865.e752; quiz:e14-55. doi: 10.1053/j.gastro.2013.04.048

63. Lakatos PL, Peyrin-Biroulet L. Azathioprine in early Crohn's disease: time to revisit patient selection and end points for clinical trials and/or azathioprine efficacy? Gastroenterology. (2014) 146:867-8. doi: 10.1053/j.gastro.2013.11.053

64. Rammohan H, Pai CG. Shrinking indications for azathioprine in Crohn's disease: a conclusion too premature? Gastroenterology. (2014) 146:866-7. doi: 10.1053/j.gastro.2013.10.071

65. Shi HY, Chan FK, Leung WK, Li MK, Leung CM, Sze SF, et al Low-dose azathioprine is effective in maintaining remission in steroiddependent ulcerative colitis: results from a territory-wide Chinese population-based IBD registry. Therap Adv Gastroenterol. (2016) 9:449-56. doi: $10.1177 / 1756283 X 16643509$

66. Yang SK, Hong M, Baek J, Choi H, Zhao W, Jung Y, et al. A common missense variant in NUDT15 confers susceptibility to thiopurine-induced leukopenia. Nat Genet. (2014) 46:1017-20. doi: 10.1038/ng.3060

67. Al-Judaibi B, Schwarz U, Huda N, Dresser G, Gregor J, Ponich T, et al. Genetic predictors of azathioprine toxicity and clinical response in patients with inflammatory bowel disease. J Popul Ther Clin Pharmacol. (2016) 23:e26-36

68. Choi JM, McGovern DP, Lee ES, Berel D, Kwon S, Landers CJ, et al. Predictors of therapeutic remission to thiopurines in pediatric inflammatory bowel disease. Gastroenterology. (2011) 140:S-154. doi: 10.1016/S0016-5085(11)60623-9

69. Cuffari C, Theoret Y, Latour S, Seidman G. 6-Mercaptopurine metabolism in Crohn's disease: correlation with efficacy and toxicity. Gut. (1996) 39:401-6. doi: 10.1136/gut.39.3.401

70. Osterman MT, Kundu R, Lichtenstein GR, Lewis JD. Association of 6-thioguanine nucleotide levels and inflammatory bowel disease activity: a meta-analysis. Gastroenterology. (2006) 130:1047-53. doi: 10.1053/j.gastro.2006.01.046

71. Moon W, Loftus EV Jr. Recent advances in pharmacogenetics and pharmacokinetics for safe and effective thiopurine therapy in inflammatory bowel disease. Aliment Pharmacol Ther. (2016) 43:863-83. doi: 10.1111/apt.13559

72. Gonzalez-Lama Y, Bermejo F, Lopez-Sanroman A, Garcia-Sanchez V, Esteve $\mathrm{M}$, Cabriada JL, et al. Thiopurine methyl-transferase activity and azathioprine metabolite concentrations do not predict clinical outcome in thiopurinetreated inflammatory bowel disease patients. Aliment Pharmacol Ther. (2011) 34:544-54. doi: 10.1111/j.1365-2036.2011.04756.x

73. Schnitzler F, Fidder H, Ferrante M, Noman M, Arijs I, Van Assche G, et al. Mucosal healing predicts long-term outcome of maintenance therapy with infliximab in Crohn's disease. Inflamm Bowel Dis. (2009) 15:1295-301. doi: 10.1002/ibd.20927

74. Baert F, Moortgat L, Van Assche G, Caenepeel P, Vergauwe P, De Vos $\mathrm{M}$, et al. Mucosal healing predicts sustained clinical remission in patients with early-stage Crohn's disease. Gastroenterology. (2010) 138:463-8. doi: $10.1053 /$ j.gastro.2009.09.056

75. Mao R, Guo J, Luber R, Chen BL, He Y, Zeng ZR, et al. 6-Thioguanine nucleotide levels are associated with mucosal healing in patients with Crohn's disease. Inflamm Bowel Dis. (2018) 24:2621-7. doi: 10.1093/ibd/izy173 
76. Meijer B, Wilhelm AJ, Mulder CJ, Bouma G, Van Bodegraven AA, De Boer NK. Pharmacology of thiopurine therapy in inflammatory bowel disease and complete blood cell count outcomes: a 5-year database study. Ther Drug Monit. (2017) 39:399-405. doi: 10.1097/FTD.0000000000000414

77. Smith M, Blaker P, Patel C, Marinaki A, Arenas M, Escuredo E, et al. The impact of introducing thioguanine nucleotide monitoring into an inflammatory bowel disease clinic. Int J Clin Pract. (2013) 67:161-9. doi: 10.1111/ijcp.12039

78. Feuerstein J, Nguyen G, Kupfer S, Falck-Ytter Y, Singh S. American gastroenterological association institute guideline on therapeutic drug monitoring in inflammatory bowel disease. Gastroenterology. (2017) 153:82734. doi: 10.1053/j.gastro.2017.07.032

79. Warner B, Johnston E, Arenas-Hernandez M, Marinaki A, Irving P, Sanderson J. A practical guide to thiopurine prescribing and monitoring in IBD. Frontline Gastroenterol. (2018) 9:10-5. doi: 10.1136/flgastro-2016-100738

80. Haines ML, Ajlouni Y, Irving PM, Sparrow MP, Rose R, Gearry RB, et al. Clinical usefulness of therapeutic drug monitoring of thiopurines in patients with inadequately controlled inflammatory bowel disease. Inflamm Bowel Dis. (2010) 17:1301-7. doi: 10.1002/ibd.21458

81. Goldberg R, Moore G, Cunningham G, Schulberg J, Marsh P, Brown S, et al. Thiopurine metabolite testing in inflammatory bowel disease. J Gastroenterol Hepatol. (2016) 31:553-60. doi: 10.1111/jgh.13210

82. Reinshagen M, Schütz E, Armstrong VW, Behrens C, Von Tirpitz C, Stallmach A, et al. 6-thioguanine nucleotide-adapted azathioprine therapy does not lead to higher remission rates than standard therapy in chronic active Crohn disease: results from a randomized, controlled, open trial. Clin Chem. (2007) 53:1306-14. doi: 10.1373/clinchem.2007.086215

83. Dassopoulos T, Dubinsky MC, Bentsen JL, Martin CF, Galanko JA, Seidman EG, et al. Randomised clinical trial: individualised vs. weight-based dosing of azathioprine in Crohn's disease. Aliment Pharmacol Ther. (2014) 39:163-75. doi: 10.1111/apt.12555

84. Chouchana L, Narjoz C, Beaune P, Loriot MA, Roblin X. the benefits of pharmacogenetics for improving thiopurine therapy in inflammatory bowel disease. Aliment Pharmacol Ther. (2012) 35:15-36. doi: 10.1111/j.1365-2036.2011.04905.x

85. Sparrow M, Hande S, Friedman S, Lim W, Reddy S, Cao D, et al. Allopurinol safely and effectively optimizes tioguanine metabolites in inflammatory bowel disease patients not responding to azathioprine and mercaptopurine. Aliment Pharmacol Ther. (2005) 22:441-6. doi: 10.1111/j.1365-2036.2005.02583.x

86. Ansari A, Patel N, Sanderson J, O’Donohue J, Duley J, Florin T. Low-dose azathioprine or mercaptopurine in combination with allopurinol can bypass many adverse drug reactions in patients with inflammatory bowel disease. Aliment Pharmacol Ther. (2010) 31:640-7. doi: 10.1111/j.1365-2036.2009.04221.x

87. Kreijne JE, de Veer RC, de Boer NK, Dijkstra G, West R, Moorsel SA, et al. Real-life study of safety of thiopurine-allopurinol combination therapy in inflammatory bowel disease: myelotoxicity and hepatotoxicity rarely affect maintenance treatment. Aliment Pharmacol Ther. (2019) 50:407-15. doi: 10.1111/apt.15402

88. Kiszka-Kanowitz M, Theede K, Mertz-Nielsen A. Randomized clinical trial: a pilot study comparing efficacy of low-dose azathioprine and allopurinol to azathioprine on clinical outcomes in inflammatory bowel disease. Scand J Gastroenterol. (2016) 51:1470-5. doi: 10.1080/00365521.2016. 1216589

89. Kwan L, Devlin S, Mirocha J, Papadakis K. Thiopurine methyltransferase activity combined with 6-thioguanine metabolite levels predicts clinical response to thiopurines in patients with inflammatory bowel disease. Dig Liver Dis. (2008) 40:425-32. doi: 10.1016/j.dld.2008.01.003

90. Coenen MJ, de Jong DJ, van Marrewijk CJ, Derijks LJ, Vermeulen SH, Wong DR, et al. Identification of patients with variants in TPMT and dose reduction reduces hematologic events during thiopurine treatment of inflammatory bowel disease. Gastroenterology. (2015) 149:907-17.e7. doi: 10.1053/j.gastro.2015.06.002

Conflict of Interest: SH has received lecture fees from Pfizer, Janssen, and Takeda PI has received fees for speaking on behalf of or acting in an advisory capacity for AbbVie, Arena, Celgene, Ferring, Prometheus, Shire, Warner Chilcott, Takeda, MSD, Vifor Pharma, Pharmacosmos, Topivert, Genentech, Hospira, Samsung Bioepis, VH2, Janssen, Sandoz, Lilly, Roche and has received financial support for research from MSD, Pfizer, and Takeda.

The remaining authors declare that the research was conducted in the absence of any commercial or financial relationships that could be construed as a potential conflict of interest.

Copyright (c) 2019 Luber, Honap, Cunningham and Irving. This is an open-access article distributed under the terms of the Creative Commons Attribution License (CC $B Y)$. The use, distribution or reproduction in other forums is permitted, provided the original author(s) and the copyright owner(s) are credited and that the original publication in this journal is cited, in accordance with accepted academic practice. No use, distribution or reproduction is permitted which does not comply with these terms. 